\title{
DESIGNING RISK MANAGEMENT: APPLYING VALUE STREAM MAPPING TO RISK MANAGEMENT
}

\author{
Willumsen, Pelle (1); Oehmen, Josef (1); Rossi, Monica (2) \\ 1: Danish Technical University (DTU); 2: Polytecnic de Milan
}

\begin{abstract}
Risk management (RM) in new product development (NPD) is often implemented as a standardized framework and ends up being carried out as a tick the box, non-value adding activity. To avoid this problem, RM needs to be tailored to the organization and NPD project. This paper identifies a gap in both understanding and facilitating tailoring, i.e. design of RM systems in NPD. To understand how to design RM systems, we must better understand how RM adds value to NPD activities. We applied Product Development Value Stream Mapping (PDVSM) to RM and conceptualized a Risk Value Stream Mapping (RVSM) framework to support design. Through a state-of-the-art literature review, we identified typical categories of value and waste in RM as well as approaches to model the RM in NPD. We developed and tested components of the RVSM framework based on PDVSM in three case companies. In this paper, results are presented regarding waste, value and potential ways to model the value stream in RM. The framework enables a diagnosis of the current state of RM in companies and supports future design activities pertaining to RM systems. This paper is positioned at the intersection of design, lean thinking and RM
\end{abstract}

Keywords: Risk management, New product development, Lean design

\section{Contact:}

Willumsen, Pelle

Danish Technical University (DTU)

Management engineering

Denmark

pwil@dtu.dk 


\section{INTRODUCTION}

Risk management (RM) is an integral part of new product development (PD). Risks are at the heart of innovation and managers should learn to explicate and embrace the risks that matter (Wang and Yang, 2012). Companies accept a trade-off between risks and benefits, because risk taking is inherent to progress and PD. However, while companies require a strategy that involves both taking and avoiding risks in order to survive, they are often unable to protect themselves against risks effectively and efficiently (Choi et al., 2010). In PD risk can cause products and/or projects to fail. Risk can cause delays, increase costs, and have consequences for a project and the company as a whole (Salavati et al., 2016). Without proper RM, PD projects can easily run out of control, consume resources and experience cost overruns which might lead to failure (Mu et al., 2009). About $80 \%$ of PD projects fail before project completion and 50\% of completed projects make no return on the investment (Cooper, 2003). Over time, RM has become part of PD (Unger and Eppinger, 2011) and can add value to the PD process (Mu et al., 2009). However, the value of RM in PD depends on how it is executed. In this paper risk is defined as "the effect of uncertainty on objectives" (ISO 31000, 2018, p.1) and RM as "coordinated activities to direct and control and organization with regard to risk" (ISO 31000, 2018, p.1). There is no final consensus yet on terms and definitions in RM (Aven, 2012) and the current definitions are problematic to some extent. We chose to adopt the ISO definitions of risk and RM because they are among the most generic and least problematic (Aven, 2012). In many cases, RM can end up disconnected from the value creation of the engineering tasks and executed as a tick-the-box activity to satisfy compliance demands (Hubbard, 2009; Kutsch et al., 2014; Kutsch and Hall, 2009; Oehmen et al., 2012). Škec et al. (2014) argue that there is no 'one size fits all' and that RM must be tailored to the PD environment. According to Oehmen et al. (2014) tailoring RM is a key practice to enable RM to add value to PD. A benefit of tailoring the RM process is that this can enable it to support innovation better (Vasconcellos et al., 2011). The ISO 31000 standard recognizes the need for tailoring. However, according to Olechowski et al. (2016) it is unclear how to tailor RM and ISO 31000 does not go into detail regarding how to do so (ISO 31000 , 2018). Furthermore, Leitch (2010) identified problems with its implementation requirements. Tegeltija (2018) provides more detail regarding which parameters are important in tailoring: Central aspects of tailoring include stakeholder needs and perceptions, strategic objectives and integration with other processes in the organization (Willumsen et al., 2019). Multiple authors have studied the application of RM practices in different environments and have found that they are often not implemented at a satisfactory level or are perceived to not create value (Kutsch and Hall, 2009; Raz et al., 2002; Ren and Yeo, 2004) and that there is a gap regarding how to tailor RM to PD projects (Škec et al., 2014; Tegeltija et al., 2018). Many interests come together in the RM process and there might be strategic risks that are very important at the upper management level, but which are not considered important at the project level and vice versa. Different stakeholders have different needs in relation to the purpose of the RM process and stakeholders might therefore see different risks as important. This affects how and which RM activities are considered to be value creating (Krane et al., 2012; Willumsen et al., 2019). Therefore we argue that an important criterion to judge an implementation of RM, is if and how well it is tailored to create value for stakeholders in a particular context. While previous studies have focused on various parameters to tailor too, we focus on both what to tailor to and how to tailor it. To address these aspects of RM tailoring, we applied and contextualized the concept of value stream mapping to RM in PD. This is a suitable approach because it addresses stakeholder needs and process improvement and provides an approach to conceptualizing the design of processes (Willumsen et al., 2017). The purpose of this study was to better understand how value stream mapping can be used to tailor RM. Product development value stream mapping (PDVSM) is an approach that explicates stakeholder needs and their utilization in process improvement, i.e. tailoring the PD process to stakeholder needs is a core part of the purpose of PDVSM. In this paper, we investigated central elements of PDVSM: value, waste and how to model the value stream (McManus, 2005), and conceptualized and contextualized what their equivalent would be in RM. PDVSM has a proven track record in PD, and is one of the most widely applied methods of Lean PD.

While risk reduction is mentioned as an aspect of value in the original PDVSM, there is no specific guidance on how to optimize the process in terms of risk management. There is no guidance on how to undertake value stream mapping of the RM process in $\mathrm{PD}$, in order to maximize its value and minimize its waste. This is the main contribution of this paper. The remainder of this paper is structured as follows: 
We first present a brief overview of value, waste and the value stream as defined in PDVSM (Section 2), followed by a conceptualization of a Risk Value Stream Mapping (RVSM) framework based on literature (Section 3), mirroring the categories of value, waste and the value stream. We introduce the case research method (Section 4) and present the results of applying RVSM at three case companies involved in PD (Section 5), with the goal of further refining the framework. The results are discussed (Section 6) and finally conclusions are provided (Section 7).

\section{LITERATURE BACKGROUND: CORE CONCEPTS OF PDVSM}

Three core concepts form the basis of PDVSM (McManus, 2005): 1. articulating the value for stakeholders ('value'), 2. identifying wasteful activities in the PD process ('waste') and 3. developing a model of the PD process, visualizing activities, the waste they might include, and their contribution to creating value ('value stream'). This section comprises a brief description of these core concepts. In the next section their equivalent concepts for RVSM will be conceptualized. McManus (2005) argues that a task can create value in multiple ways in PD and that there are multiple aspects of value. Aspects of value touch on creating value for different outcomes, including project outputs, organizational processes and personal outcomes. In PDVSM, the key stakeholders expectations to the process and its outputs need to be identified because they partly determine the value. When a process step contributes to: 'enabling other tasks, 'definition of processes to deliver project' or 'facilitating communication', it creates value for organizational outcomes and processes. When a process step contributes to the definition of the end product with the desired functional performance it contributes to creating value for the product's performance. Thus, process steps can create value in multiple ways in PDVSM, and there are multiple stakeholders that may have differing understandings of what value is. The value considered to be important will vary according to contexts and so, the objective of the process improvement will vary as well. The key objectives of optimizing processes through lean are to make them effective, i.e. value adding for stakeholders, and efficient, i.e. maximize value generation with minimal resource utilization.

Rossi et al. (2017) defines waste as any process step that uses resources without adding any value for the customer, i.e. non-value adding process steps. In lean PD, Oehmen et al. (2010) defines the different types of waste as: overproduction of information, over processing of information, miscommunication of information, stockpiling of information, generating defective information, correcting information, waiting of people and unnecessary movement of people. 'Waiting' waste, was further investigated by Kato (2005), who uncovered the phenomenon of 'Information Rot': When information is created in PD but not used in a timely manner, part of it will become obsolete as time passes. This 'rotten' information will require rework (if discovered), or cause quality issues (if not discovered). The waste of using 'defective information' has been shown in multiple studies to be one of the major drivers of unplanned work in PD. It can affect downstream decisions and processes causing errors that spiral out of control and cause rework (Graebsch et al., 2007).

According to McManus (2005) the value stream in PDVSM is defined as process steps and flows of information. The literature conceptualizes the value stream in PD in differing ways and highlights different types of information flows, each leading to different resolutions and foci in the mapping: Slack (1999) defined four types of value streams in PD; product, project, process and business information. In response, Graebsch et al. (2007) reduced it to: process and product information flow. In summary, the value stream consist of process steps and differing types of information flow.

\section{LITERATURE BASED CONCEPTULIZATION OF PDVSM FOR RM}

In order to develop a prototype of RVSM it is necessary to reconceptualize the three abovementioned elements of PDVSM in the context of PD RM: value, waste and value stream.

\subsection{Value in PD RM}

The first principle of the ISO 31000 standard is that RM should create and protect value (ISO 31000, 2018). However it is not clear which value the standard is referring to. In RM in PD, the value is often considered to be its contribution to project success. Mu et al. (2009) provide empirical evidence that RM impacts project output and the performance of PD. However, Oehmen et al. (2014) provide evidence that the link to project or product success is not direct, rather the link is indirect because RM creates value by enabling other processes, which then influence product and project success. Researchers who try to 
establish causal links between RM and project or product success produce conflicting results (de Bakker et al., 2010; De Carvalho and Rabechini Junior, 2015; Oehmen et al., 2014) and face limitations due to complexity, sample size, effects of uncertainty and other compounding factors. According to Krane et al. (2012), there are variations in how stakeholders perceive the importance of risk and which objectives are important in a project, because project manager's (PM) and project owners for instance focus on different objectives, typically at the strategic and project levels. Therefore, the value stakeholders perceives RM should create will vary. There are many aspects of value creation in RM that define what the value of RM is in a specific context. It can create value for different types of outcomes such as product performance, project output, strategic benefits and other organizational processes and outcomes (Willumsen et al., 2019). For instance, if a stakeholder's objective is to be on cost then RM activities that help to manage risks that may affect this objective will be considered valuable by that stakeholder, while others might consider other objectives valuable (Willumsen et al., 2019). RM is typically considered to create value through a series of process steps. There are multiple ways in which the process steps are defined. For detailed information see Kutsch et al. (2009). In this study we chose to follow the process steps defined by the ISO standard: Establish the context, risk identification, risk assessment, risk evaluation, risk treatment, communication, monitoring and control (ISO 31000, 2018). Recent studies produce conflicting results on what the value creating practices of RM are. According to Oehmen et al. (2014) $70 \%$ of best practices have no confirmable effect, (i.e. value). Oehmen (2014) argue that a primary way RM create value is by supporting decision making. In summary, RM adds value by improving the quality of processes and decision making in risk related matters at different levels of an organization, for instance by adding information about risk to a decision-making situation and thus improving the decision makers' ability to evaluate alternatives. The value that RM adds is contextual and determined by the project or strategic objectives that a stakeholder perceives to be important. Thus, an RM activity is considered to create value if it improves other processes and/or helps to protect project or strategic objectives. There are many facets to RM value creation that are discussed in detail by Willumsen et al. (2019).

\subsection{Waste in PD RM}

There are multiple examples of waste within the RM literature, that are defined as non-value adding RM. Implementing too much RM can lead to overproduction of RM information and doing too little RM can create an unsound basis for decision making. Beauregaard et al. (2015) reports a case study that resembles a clear example of overproduction: In their case study, implementation of RM according to the ISO 31000 standard, produced so much information that the engineers were unable to make sense of it, thus impacting and impairing decision-making. In a case reported by (Peterson, 2005), a risk register was developed but not included in the analysis, leading to failure. This can be identified as the overproduction of information; however, the output of the analysis can be classified as defective information, thus demonstrating a connection between waste phenomena in RM. Skelton et al. (2003) identified rework in RM. The lack of frontloading can lead to rework of the information regarding the understanding of risks in PD. Information rot also occur in RM. Risk analysis is often carried out at the beginning of a project and not utilized until later. There are examples of delays in the RM process due to the link with other decision making processes. The RM information can sometimes be considered to be waiting and information rot occur in RM as information becomes obsolete (Renault et al., 2016; Yaraghi and Langhe, 2011). Hubbard (2009) pinpoints the dangers of using defective information in RM as one of the main causes of RM failure. Defective information can be caused by using an inappropriate method, applying a method in an incomplete way, a lack of data or failure to communicate the quality of the data. Performing RM based on defective information can be worse than implementing no RM at all (Hubbard, 2009). RM can become a separate task that is disconnected from the value creation of the development tasks (Kutsch et al., 2014; Kutsch and Hall, 2009; Oehmen et al., 2012), thus producing defective information and no value for the engineering tasks. We conceptualize waste in RM as nonvalue adding activities that cause one or more of the following: defective information, overproduction of information, information that 'waits', unnecessary rework; and information rot.

\subsection{Value stream in PD RM}

Following the definition of value stream in PDVSM, we consider process steps and information flows in RM. Willumsen et al. (2017) conceptualized the value stream in PD RM as consisting of all risk related activities, as well as key decision points in a project. Following the ISO definition of risk and 
RM means that many activities in PD could be classified as risk related, and could be mapped as part of the value stream. For instance, there are activities in PD that help to identify and reduce the effect of uncertainty on project objectives (i.e. risk identification and assessment), such as prototyping (Ouden, 2012) or technology readiness levels, which for example, serve to assess the effect of uncertainty on objectives with regard to the use of a particular technology (Ilevbare et al., 2014). When mapping the current value stream in PD, we thus consider formal risk related activities, as well as activities that serve a similar purpose (informal RM). To improve RM in terms of effectiveness and efficiency, it is crucial to identify both formal and informal RM (Murtonen, 2009). A central aspect of the value stream in RM is the information flow regarding risk and uncertainty. This can be divided into information flow about various sources of uncertainty, such as technical, market and organizational (Mu et al., 2009). The information flow can be manifested through dialogue and/or items such as risk reports, risk logs, risk matrices and many other documents and models. In the section on the value of RM (sec. 3.1) it was argued that RM added value indirectly through other processes. Therefore, processes that need risk information, such as decision points, should be mapped. As PD tasks can contribute to the reduction of uncertainty (McManus, 2005), it could be important to map the PD process and identify which process steps are related to the management of risk. The process steps in PD that serve to manage risk (informal RM) can be identified through the ISO process step categories described in section 3.1. In summary we conceptualize the RM value stream as: 1 . Formal RM process steps (i.e. as proposed by the ISO 31000), 2. PD activities that serve to manage risk (informal RM), 3. Risk related information flows and, 4. Key decision points in the PD process. The conceptual RVSM framework contains the following tasks (example depicted in figure 1):

1) Map key decision points, 2) Map formal RM process steps, 3) Map PD process steps that serve to manage risk (informal RM), 4) Map risk related information flows, 5) Categorize according to ISO 31000 process steps, 6) Evaluate the value added by each process step for stakeholders and other processes, and 7) Identify waste.

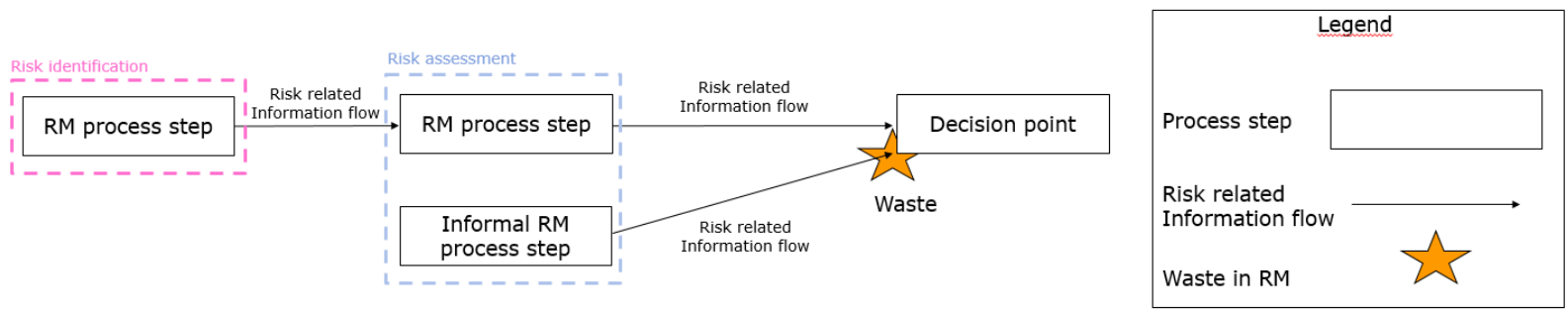

Figure 1 - Risk value stream mapping (RVSM) conceptual framework

\section{METHOD}

Three exploratory case studies were carried out in companies involved in PD, in order to refine our preliminary literature-based RVSM framework. The companies are involved complex engineering products utilizing both hard- and software. Each case included R\&D and management and other parts of the organization. Sampling within the organization was conducted by means of the snowballing method (Bryman and Bell, 2015). A case study approach was selected because the phenomena of tailoring RM in PD is not well understood in practice. Case studies allow for rich understanding of the context (Yin, 2003) which is a central part of optimizing and tailoring and thus an appropriate way to evaluate the framework. We used the case studies to explore the RVSM concepts conceptualized from our literature study and to evaluate the RVSM in an industry context. We chose to sample medium to large companies that faced critical risks and challenges with RM. The companies had a high need for RM and ambitions to improve their management of risk, due to the volatility of their industry context. The companies had experienced issues that had been traced to RM and were thus suitable cases for studying waste, value and the value stream. The number of interviewees were: thirteen in case 1 , twelve in case 2 and five interviews in case 3 (still ongoing).

\begin{tabular}{|c|c|c|c|c|}
\hline & Industry & Data collection & Interviewees & Company size \\
\hline Case 1 & $\begin{array}{l}\text { Processing } \\
\text { equipment product } \\
\text { development }\end{array}$ & $\begin{array}{l}\text { Interviews, PD process } \\
\text { documents, observations }\end{array}$ & $\begin{array}{l}\text { Project managers, } \\
\text { program managers, } \\
\text { team members }\end{array}$ & Large \\
\hline
\end{tabular}




\begin{tabular}{|l|l|l|l|l|}
\hline Case 2 & $\begin{array}{l}\text { Industrial product } \\
\text { development }\end{array}$ & $\begin{array}{l}\text { Interviews, PD process } \\
\text { documents, observations }\end{array}$ & $\begin{array}{l}\text { Project managers, } \\
\text { program managers, } \\
\text { team members, } \\
\text { PMO, VP }\end{array}$ & Large \\
\hline Case 3 & $\begin{array}{l}\text { Medico product } \\
\text { development }\end{array}$ & $\begin{array}{l}\text { Interviews, PD process } \\
\text { documents, observations }\end{array}$ & $\begin{array}{l}\text { Project managers, } \\
\text { program managers, } \\
\text { team members, } \\
\text { upper management }\end{array}$ & Medium \\
\hline
\end{tabular}

We initially used a process of grounded coding and abductive reasoning (Gioia et al., 2013) iterating with literature on RM, PD and value stream mapping. We utilized the conceptualizations of value, waste value stream as described in the literature section as a frame of reference in the coding. The conceptualization of RVSM as described in section 3 was deployed in each case. The framework originated from PDVSM and from Willumsen et al. (2017). We utilized multiple types of data in the form of interviews that typically lasted 60 minutes, project and RM documents as well as PD process documentation and observations, workshops and follow-up interviews. Parts of the PD process were mapped out in each case based on comparing input from multiple employees, documents and observations. Multiple approaches to mapping the processes were tested, as well as multiple conceptualizations of what the RM process was considered to be. The first iterations consisted of mapping out formal RM procedures. Later iterations involved mapping out parts of the PD process, decision points and classifying the various process elements according to their relation to RM, and identifying the RM properties of existing PD properties, i.e. informal RM. Thereafter, waste was identified in the process.

\section{RESULTS}

In the following we present the empirical findings of the three case studies in relation to the three central aspects of RVSM, namely value, waste and value stream.

\subsection{Waste in RM}

As an overall finding, the case studies showed that addressing 'waste in PD RM' made intuitive sense to the participants. It created an intuitive understanding for analyzing the root causes of process deficiencies. Results are shown in Table 1.

Table 1 Empirical results - waste in RM

\section{Waste in RM \\ Defective information}

Over production

Stockpiling information

Unnecessary movement of people

Rework

\section{Illustrative quote}

"The things that kills or stalls a project is never in the risk-matrix" (PM, case 2)

"You have to deliver a risk matrix, but how you got there doesn't matter" (PM, case 2)

"if it is just a checklist sitting somewhere, then people don't use it, and it becomes a wasted effort" (program manager, case 3)

"we're uncertain what are the monetary effect of the risk as this early stage, I think it would make more sense to do after" ( project team member, case 1)

"It can be time consuming walking around to get information [about risk]" (PM, case 1)

"Time spend in risk identification is always little in the beginning of a project because everybody wants to start and then do the first part as quickly as possible."

(PM, case 1)

\section{Examples}

Missing stakeholder viewpoints, poor RM process, lack of considering multiple sources of uncertainty, poor input data, lack of sharing information Missing standardization, serial processing and creation of similar documents, reports are not used after creation Documented risk lay around unutilized

Lack of documentation, risks only retrievable by going around asking employees Low quality initial work, 'tickthe-box' risk management 
Information rot was observed to occur in RM documents such as risk matrices and risk logs in all cases. The documents were supposed to be updated and re-evaluated, but was not, thus becoming partially obsolete over time. Defective information was identified as one of the main categories of waste. Defective information was often caused by either poor process or poor input data. The empirical results on waste contributed to the framework by identifying waste categories that were not identified in the literature studies on RM (Unnecessary movement of people, stockpiling), as well as confirming defective information as a central category.

\subsection{Value in RM}

We expected to uncover a range of value perceptions regarding RM in PD, and the case studies confirmed that expectation. More interestingly, while practically all the participants were used to conversations around the 'value that our PD process generates', most of them had trouble articulating the value they expected from RM. In case study 1, there was a need to compare projects at the portfolio level: "As a manager you have to prioritize between projects, and so on." This was related to evaluating the risk level of the projects. In this example, RM could add value by enabling a portfolio manager to compare the level of risk for different projects and better address resource allocation. In case 1, an important value proposition was to support the process of concept selection. In all the case studies the interviewees identified a key need to support decision making with RM results, because they had made poor decisions in the past. The need to support other organizational processes beyond decisions such as exploration of the solution space was also apparent: "We could also explore regulatory strategies, you could explore the business side of things, [,,,] here, RM probably should be very present. Because what you choose depends on how risky it is" (PM, case 3 ).

RM was perceived to impact organizational outcomes regarding communication: "A risk analysis is actually more a way to communicate and get fine-tuned rather than placing a number in a matrix". The interviewees stated that RM could create more value if they received "help to e.g. facilitate the identification of risks just as project managers can get help from other specialists" (PM, case 2). Documenting was perceived to enable value creation as the lack there of had caused problems in the past: "We ended up with another team having to take over the project because the team doing first implementation was not willing to document" (PMO, case 2). The interviewees had difficulty being concise regarding what value RM should create for the company, yet pinpointed many errors due to problems with RM. Variations in the perceptions of the importance of RM were identified: "No, this risk is not prioritized in relation to what is important to us. There are lot of things that we have to manage before risks". There were examples of conflicting perspectives regarding what output RM should create value for, for instance between performance of the product and the schedule: "what we could do better is to listen when an expert says something. Not to push the expert to do something faster just to get it out faster" (PM, case 3). The results contributed to the framework by confirming the need for a multifaceted, stakeholder focused, contextual understanding of the value of RM.

\subsection{Value stream in RM}

In all cases there were examples of using on only part of an RM process or there were disconnects in the value stream. This was discovered by mapping according to the ISO process steps. This resulted in multiple types of waste, such as defective information, over production, miscommunication leading to a poor basis for decision-making. Some PD projects did not have much formal RM process. By mapping the PD process it was possible to identify that in those projects there were activities that served to manage risk, but they were not denoted as RM. For instance, a process called technical review in case 1 served as risk identification and risk assessment. This kind of knowledge can assist in tailoring the RM by understanding the actual current state and to avoid doubling RM activities. The companies in the case studies did not have a clear understanding of what RM was being performed and our approach to mapping the value stream in RM made it more explicit than it had been before. In case 2, the formal RM activities of risk identification using a risk matrix was perceived to be wasteful, yet solving anticipated technical problems were perceived as valuable, both could be considered activities to manage risk. Mapping both formal and informal RM provided a more complete overview and thus contributed to the framework by confirming the value of the approach. In case 3 the value stream was modelled as a flow of information regarding different sources of uncertainty. This facilitated the identification of waste in the RM, which was localized to information flow and RM activities of a certain kind. There was much more activity in the risk value stream related to technical risk, and much waste related to other flows. Particularly regarding regulation and market risk, 
there was almost no flow of information, thus contributing knowledge to the framework of how defective information is generated in the value stream.

Particularly, decisions regarding concept selection were identified as a source of multiple wastes and potential to create value (Figure $2 \mathrm{a} \& 2 \mathrm{~b}$ ). Mapping the value stream revealed that concepts were evaluated ad hoc, estimates were miscommunicated and assumptions were not explicated, thus producing defective information regarding risk.
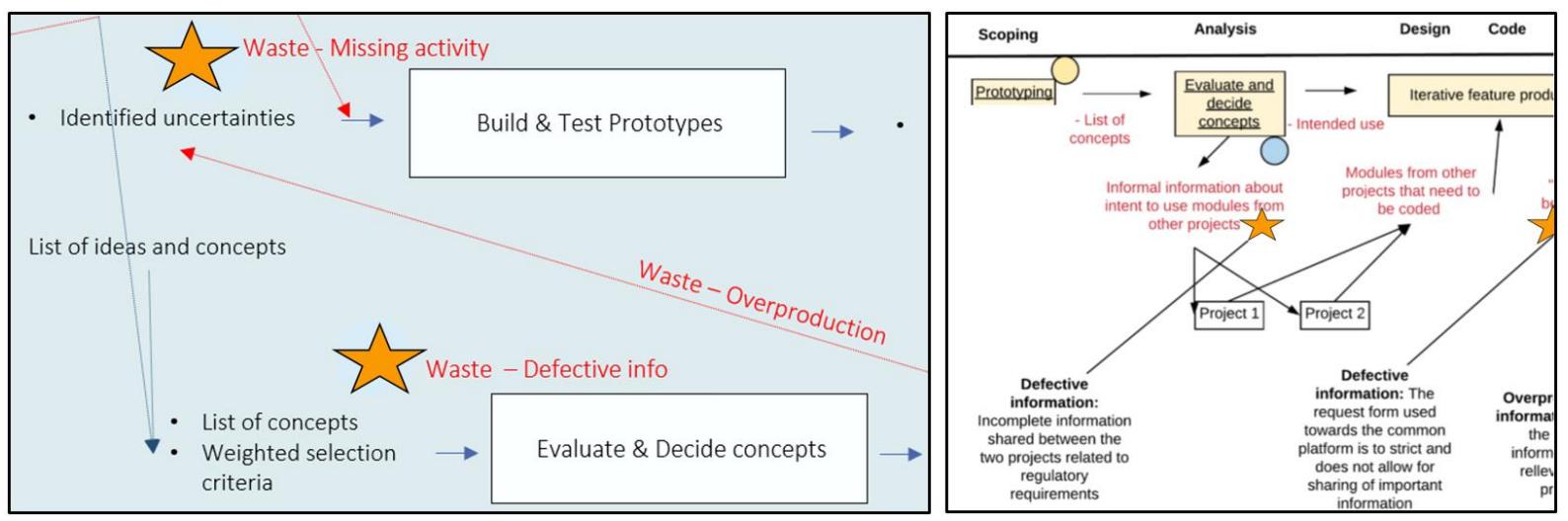

Figure $2 a \& 2 b$ - Excerpts from two examples of modelling the risk value stream

\section{DISCUSSION}

Modelling the RM process is essentially a design problem. Many approaches to process optimization could be applied to this problem. However, applying PDVSM to RM covers the central aspects of tailoring the RM. The ISO definition of RM lead to considering the value stream of both formal RM activities and informal ones, which provides a more complete picture of the actual RM as opposed to modelling only formal RM activities. As in PDVSM the value stream benefitted from more detail. When information flows regarding different sources of uncertainty were mapped it revealed that the companies were usually doing better in some areas than others, for instance excelling in managing technical risks, but failing at managing market risks. This caused problems as considering multiple sources of uncertainty is important for effective RM (Mu et al., 2009). Thus it is important to consider how to model the RM process, to tailor it for value creation. We identified defective information as the most central waste category in RM as was also identified by the literature. However, other waste categories such as the unnecessary movement of people were identified. It seems that there is a literature gap regarding an overview of how RM can be non-value adding. Neither the waste nor value of RM is systematically accounted for in the literature, yet they are needed for tailoring RM. This paper addresses this gap by providing insights into the value, waste and ways to model the RM process in PD. The identification of waste facilitated the conversation about value. The companies had not explicated why they did RM, yet found many purposes of RM, particularly related to supporting other processes, aligning projects with strategic goals and supporting decision-making. The process of explicating the value for stakeholders and waste in RM, in combination with value stream modelling, could be a viable approach to tailoring and optimizing the RM process. It is a paradox that PD teams that work in design spend so much effort to design products, but the processes to help them to manage the risks, are not tailored or designed for them. There are two levels regarding how to determine whether one implementation of RM is more optimal than another, qualitative and quantitative. On the qualitative level it is about whether it creates value for the specific contextual objective as perceived by the stakeholders. Another key aspect on the qualitative level is the reduction of waste. We can then rate different implementations qualitatively according to their ability to create value for stakeholders and reduce waste. On the quantitative level it is a matter of how to quantify aspects of value such as 'quality decision making' and the effect of RM on objectives such as project success. Measuring quantitatively remains an issue of future research in the next iteration because there are challenges with 'proving' the value of RM (Willumsen et al. 2019). The mapping of formal and informal RM proved beneficial, but this aspect is not covered by standards such as the ISO, and thus presents an opportunity for further research on the actuality of RM. This paper constitutes a first step to conceptualize value stream mapping in an RM context, contributing to knowledge about value and waste in RM, as well as how to model an RM process to improve tailoring. 


\section{CONCLUSIONS}

We conceptualized and tested three aspects of risk value stream mapping (RVSM). We transferred the core concepts of PDVSM to RM to create a conceptual framework (figure 1) for tailoring RM in PD. Specifically we conceptualized waste, value and value stream in RM by consulting the literature and conducting case studies. The empirical results show that RVSM can be an appropriate approach to tailoring RM by identifying waste and potentials for value creation through RM, thus potentially enabling RM to become value adding and efficient. In the case studies, waste and the potential for value creation through RM were identified by mapping the value stream and this created a basis for tailoring RM to the company context. We contributed to the knowledge of value, waste and the value stream in RM. These aspects should be considered in the design of RM. The PDVSM core concepts could be translated to RM, with modifications regarding the value, waste and value stream. The value creation of $\mathrm{RM}$ is often related to other processes, and it is vital to model the PD processes to uncover potential for RM value creation and RM waste. The RVSM provide the foundations of an analytical framework to diagnose and tailor RM in PD. The outlook of the research is to enhance the framework by applying it in different environments and developing support for conceptualizing the future state of RM.

\section{REFERENCES}

Aven, T. (2012), "Foundational issues in risk assessment and risk management", Risk Analysis, Vol. 32, pp. 1647-1656. https://doi.org/10.1111/j.1539-6924.2012.01798.x

Beauregard, Y. (2015), "Surprises and cost overruns: A lean risk management approach to reduce surprises and address cost overruns in aerospace product development projects", in: International Annual Conference of the American Society for Engineering Management 2015, ASEM 2015. Indianapolis, IN, pp. 249-254.

Bryman, A. and Bell, E. (2015), "Business research methods", Methods, 4th edition.

Choi, H.G., Ahn, J.O., Jeung, H.S. and Kim, J.S. (2010), "A framework for managing risks on concurrent engineering basis", International Journal of Management Science and Engineering Management, Vol. 5, pp. 44-52. https://doi.org/10.1080/17509653.2010.10671090

Cooper, L.P. (2003), "A research agenda to reduce risk in new product development through knowledge management : a practitioner perspective", Journal of Engineering and Technology Management, Vol. 20, pp. 117-140. https://doi.org/10.1016/S0923-4748(03)00007-9

de Bakker, K., Boonstra, A. and Wortmann, H. (2010), "Does risk management contribute to IT project success? A meta-analysis of empirical evidence", International Journal of Project Management, Vol. 28, pp. 493503. https://doi.org/10.1016/j.ijproman.2009.07.002

De Carvalho, M.M. and Rabechini Junior, R. (2015), "Impact of risk management on project performance: The importance of soft skills", International Journal of Production Research, Vol. 53, pp. 321-340. https://doi.org/10.1080/00207543.2014.919423

Gioia, D.A., Corley, K.G. and Hamilton, A.L. (2013), "Seeking Qualitative Rigor in Inductive Research: Notes on the Gioia Methodology", Organizational Research Methods, Vol. 16, pp. 15-31. https://doi.org/10.1177/1094428112452151

Graebsch, M., Seering, W.P. and Lindemann, U. (2007), "Assessing Information Waste in Lean Product Development", International Conference on Engineering Design pp. 1-12.

Hubbard, D.W. (2009), The Failure of Risk Management: Why It's Broken and How to Fix It., 18th ed. ed. Wiley, Hoboken, N.J.

Ilevbare, I.M., Probert, D. and Phaal, R. (2014), "Towards risk-aware roadmapping: Influencing factors and practical measures", Technovation, Vol. 34, pp. 399-409. https://doi.org/10.1016/j.technovation.2014.05.006

ISO 31000 (2018), "ISO 31000:2018. Risk management - principles and guidelines", Risk Management. https://doi.org/10.1016/S1146-609X(03)00038-9

Kato, J. (2005), "Development of a process for continuous creation of lean value in product development organizations", http://hdl.handle.net/1721.1/32351

Krane, H.P., Olsson, N.O.E. and Rolstadås, A. (2012), "How project manager-project owner interaction can work within and influence project risk management", Project Management Journal, Vol. 43, pp. 54-67. https://doi.org/10.1002/pmj.20284

Kutsch, E., Browning, T.R. and Hall, M. (2014), "Bridging the risk gap: The failure of risk management in information systems projects", Research Technology Management, Vol. 57, pp. 26-32. https://doi.org/10.5437/08956308X5702133

Kutsch, E. and Hall, M. (2009), "The rational choice of not applying project risk management in information technology projects", Project Management Journal, Vol. 40, pp. 72-81. https://doi.org/10.1002/pmj.20112

Leitch, M. (2010), "ISO 31000 : 2009 - The new international standard on risk management 30", https://doi.org/10.1111/j.1539-6924.2010.01397.x 
McManus, H.L. (2005), "Product Development Value Stream Mapping (PDVSM) manual”, The Lean Aerospace Initiative. https://doi.org/10.1161/STROKEAHA.110.611731

Mu, J., Peng, G. and MacLachlan, D.L. (2009), "Effect of risk management strategy on NPD performance", Technovation. https://doi.org/10.1016/j.technovation.2008.07.006

Murtonen, M. (2009), "Formal and informal risk management actions in projects", Project perspectives, Vol. 32, pp. $48-53$.

Oehmen, J., Olechowski, A., Robert Kenley, C. and Ben-Daya, M. (2014), “Analysis of the effect of risk management practices on the performance of new product development programs", Technovation, Vol. 34, pp. 441-453. https://doi.org/10.1016/j.technovation.2013.12.005

Oehmen, J. and Rebentisch, E. (2010), "Lean Product Development for Practitioners", LAI Paper Series - Risk Management in Lean Product Development, Lean Advancement Initiative (LAI), Cambridge, MA.

Oehmen, J., Seering, W. and Olechowski, A. (2012), "Characteristics of successful risk management in product design," in: Proceedings of the 12th International Design Conference. DESIGN 2012.

Olechowski, A., Oehmen, J., Seering, W. and Ben-Daya, M. (2016), "The professionalization of risk management: What role can the ISO 31000 risk management principles play?”, International Journal of Project Management, Vol. 34, pp. 1568-1578. https://doi.org/10.1016/j.ijproman.2016.08.002

den Ouden, E. (2012), Innovation Design: Creating value for People, Organizations and Society. Springer. https://doi.org/10.1007/978-1-4471-2268-5

Peterson, S.K. (2005), "Risk and uncertainty management-best practices and misapplications for cost and schedule estimates", Proceedings - Spe Annual Technical Conference and Exhibition.

Raz, T., Shenhar, A.J. and Dvir, D. (2002), "Risk management, project success, and technological uncertainty", R\&D Management, Vol. 32, pp. 101-109. https://doi.org/10.1111/1467-9310.00243

Ren, Y.T. and Yeo, K.T. (2004), "Risk Management Capability Maturity Model for Complex Product Systems (CoPS) Projects", in: International Engineering Management Conference, pp. 807-811.

Renault, B.Y., Agumba, J.N. and Balogun, O.A. (2016), "Drivers for and Obstacles to Enterprise Risk Management in Construction Firms: A Literature Review”, in: Procedia Engineering. https://doi.org/10.1016/j.proeng.2016.11.637

Rossi, M., Morgan, J. and Shook, J. (2017), "Lean Product and Process Development”, in: Netland, T.H. and Powell, D. (Ed.), The Routledge Companion to Lean Management. Routledge, New York.

Salavati, M., Tuyserkani, M., Mousavi, S.A., Falahi, N. and Abdi, F. (2016), "Improving new product development performance by risk management", Journal of Business and Industrial Marketing. https://doi.org/10.1108/JBIM-04-2013-0090

Škec, S., Štorga, M., Rohde, D. and Marjanović, D. (2014), "Tailoring risk management approach for the product development environment", Proceedings of the 13th International Design Conference (DESIGN 2014).

Skelton, T.M. and Thamhain, H.J. (2003), "The human side of managing risks in high-tech product developments", in: IEMC-2003 PROCEEDINGS. https://doi.org/10.1109/IEMC.2003.1252344

Slack, R.A. (1999), "The lean value principle in military aerospace product development", The Lean Aerospace Initiative, Vol. 17.

Tegeltija, M., Oehmen, J., McMahon, C.A., Maier, A., Kozin, I. and Škec, S. (2018), Tailoring Risk Management in Design pp. 667-678. https://doi.org/10.21278/idc.2018.0385

Unger, D. and Eppinger, S. (2011), "Improving product development process design: a method for managing information flows, risks, and iterations”, Journal of Engineering Design, Vol. 22, pp. 689-699. https://doi.org/10.1080/09544828.2010.524886

Vasconcellos, V., Grubisic, F. and Gidel, T. (2011), "Recommendations for risk identification method selection according to product design and project management maturity", Product Innovation Degree and Project, in: International Conference on Engineering Design. pp. 187-198.

Wang, J. and Yang, C.-Y. (2012), "Flexibility planning for managing R\&amp;D projects under risk", International Journal of Production Economics, Vol. 135, pp. 823-831. https://doi.org/10.1016/j.ijpe.2011.10.020

Willumsen, P., Oehmen, J., Rossi, M. and Welo, T. (2017), “Applying lean thinking to risk management in product development", in: Proceedings of the International Conference on Engineering Design, ICED.

Willumsen, P.L., Oehmen, J., Stingl, V. and Geraldi, J. (2019), "Value creation through project risk management", International Journal of Project Management - Article in Press. https://doi.org/https://doi.org/10.1016/j.ijproman.2019.01.007

Yaraghi, N. and Langhe, R.G. (2011), "Critical success factors for risk management systems", Journal of Risk Research, Vol. 14, pp. 551-581. https://doi.org/10.1080/13669877.2010.547253

Yin, R.K. (2003), "Case study methodology R.K. Yin” (2003, 3rd edition). Case Study Research design and methods. Sage, Thousand Oaks (CA)..pdf, in: Case Study Research: Design and Methods. pp. 19-39; 96-106.

\section{ACKNOWLEDGEMENTS}

Part of the research presented is supported by Lincoln H2020 European Project, Grant agreement No 727982 